\title{
Homogeneous vs. heterogeneous nucleation in water-dicarboxylic acid systems
}

\author{
A. I. Hienola ${ }^{1}$, H. Vehkamäki ${ }^{2}$, I. Riipinen ${ }^{2}$, and M. Kulmala ${ }^{2}$ \\ ${ }^{1}$ Finnish Meteorologic Institute, Erik Palmenin aukio 1, P.O. Box 503, 00101 Helsinki, Finland \\ ${ }^{2}$ Department of Physics, Division of Atmospheric Sciences and Geophysics, University of Helsinki, P.O. Box 64, \\ 00014 Helsinki, Finland
}

Received: 28 March 2008 - Published in Atmos. Chem. Phys. Discuss.: 21 October 2008

Revised: 12 January 2009 - Accepted: 13 February 2009 - Published: 17 March 2009

\begin{abstract}
Binary heterogeneous nucleation of watersuccinic/glutaric/malonic/adipic acid on nanometer-sized particles is investigated within the frame of classical heterogeneous nucleation theory. Homogeneous nucleation is also included for comparison. It is found that the nucleation probabilities depend on the contact angle and on the size of the seed particles. New thermodynamical properties, such as saturation vapor pressure, density and surface tension for all the dicarboxylic acid aqueous solutions are included in the calculations. While the new surface tension and density formulations do not bring any significant difference in the computed nucleation rate for homogeneous nucleation for succinic and glutaric acids, the use of the newly derived equations for the vapor pressure decrease the acid concentrations in gas phase by 3 orders of magnitude. According to our calculations, the binary heterogeneous nucleation of succinic acid-water and glutaric acid-water - although it requires a 3-4 orders of magnitude lower vapor concentrations than the homogeneous nucleation - cannot take place under atmospheric conditions. On the other hand binary homogeneous nucleation of adipic acid-water systems might be possible under conditions occuring in upper boundary layer. However, a more detailed characterization of the interaction between the surface and the molecules of the nucleating vapor should be considered in the future.
\end{abstract}

\section{Introduction}

An important phenomenon associated with the atmospheric aerosol system is the formation of new aerosol particles. Atmospheric aerosol formation consists of a complicated set

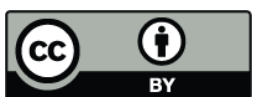

Correspondence to: A. I. Hienola (anca.hienola@fmi.fi) of processes that includes the production of nanometer-size clusters from gaseous vapours, the growth of these clusters to detectable sizes, and their simultaneous removal by coagulation with the pre-existing aerosol particle population (e.g. Kerminen et al., 2001; Kulmala, 2003). While aerosol formation has been observed to take place almost everywhere in the atmosphere (Kulmala et al., 2004b), several gaps in our knowledge regarding this phenomenon still exist. These gaps range from the basic process-level understanding of atmospheric aerosol formation to its various impacts on atmospheric chemistry, climate, human health and environment.

Nucleation can be either homogeneous (when the nucleation probability is homogeneous thorough the system, i.e., it takes place inside of an uniform medium) or heterogeneous (when the probability of nucleation is much higher around some foreign bodies than in the rest of the system). Knowledge on the exact processes governing atmospheric particle formation and the vapours participating in them is the key to quantify the global aerosol source provided by secondary particle formation. Information on the evolution of this source, on the other hand, is needed to assess the climatic effects of atmospheric aerosols. Heterogneous nucleation is proved to be important in atmospheric conditions (Kulmala et al., 2004a, 2006).

Recent studies (O'Dowd et al., 2002; Kanakidou et al., 2005; Tunved et al., 2006; Allan et al., 2006) suggest that organic compounds are likely to play a major role in the formation and growth of atmospheric aerosol particles. Aliphatic straight-chain dicarboxylic acids (general formula $\left.\mathrm{HOOC}(\mathrm{CN})_{n} \mathrm{COOH}\right)$ such as malonic $(n=1)$, succinic $(n=2)$, glutaric $(n=3)$, and adipic $(n=4)$ acids are water soluble organic acids that are commonly found in atmospheric particulate matter (Grosjean et al., 1978; Kawamura et al., 1996; Rohrl and Lammel, 2002). This implies that they partition to the condensed phase and therefore potentially participate even in the very first steps of atmospheric

Published by Copernicus Publications on behalf of the European Geosciences Union. 
nucleation and growth. Unfortunately, atmospheric observation on gas phase concentrations of these acids are rare. Recently Limbeck et al. (2005) using Teflon/quartz filter stack system, determined the gaseous and particulate $\mathrm{C} 2$ C9 dicarboxylic acids concentrations at a continental background site in central Europe (Mt. Rax) and at an urban site Vienna. The gaseous concentrations of succinic acid and glutaric acid were found to be $10^{8}-10^{9}$ molecules $/ \mathrm{cm}^{3}$ and $10^{7}-10^{8}$ molecules $/ \mathrm{cm}^{3}$, respectively, while the concentrations for malonic acid and adipic acid were usually bellow the detection limit.

In a recent paper Gaman et al. (2004) studied the binary homogeneous nucleation of water-succinic acid and water glutaric acid, concluding that the nucleation can take place only for very high concentrations of organics in gas phase, which can not be found in atmospheric conditions. However, the lack of experimental data and well established thermophysical properties for the aqueous solutions of glutaric and succinic acids caused uncertainty in the nucleation rate calculations. In recent years several publications discussing the thermodynamical properties of the organics in question have appeared. For instance, Riipinen et al. (2006) present a method for determining the saturation vapor pressure for pure succinic acid at atmospheric temperatures; the model used simulates the binary condensation/evaporation by combining basic mass and heat transfer equations. Using experimentally determined evaporation rates of nanometer-sized aqueous malonic, succinic and glutaric acid droplets together with the binary condensation model, Koponen et al. (2007) provided expressions for the liquid phase saturation vapor pressures for the above mentioned organics. New experimental data for surface tension and density of aqueous solutions of several dicarboxylic acids (including succinic and malonic acids) are provided by Hyvärinen et al. (2006). Riipinen et al. (2007) supplies new measurements for the surface tension and vapor pressure for malonic and adipic acids.

Recently, atmospheric nucleation has been observed to occur on existing atmospheric clusters (Kulmala et al., 2007b). On the other hand the fresh particles are seen to contain organic compounds (e.g. Kulmala et al., 2007a). In order to obtain some clear information on atmospheric nucleation, we will focus on the first steps of atmospheric particle formation, investigate the relevance of the heterogeneous nucleation of malonic, succinic, glutaric and adipic acids and water in atmospheric conditions and compare the likelihood of the heterogeneous and homogeneous nucleation. The theoretical framework is based on classical nucleation theory for which a brief review is given in the theory section. The description of the homogeneous and heterogeneous nucleation theory is followed by the results section where our numerical calculations are presented and discussed. Finally, the last section gives a summary of the results, discussing the reliability of the calculations, restrictions and atmospheric implications.

\section{Theory}

\subsection{Homogeneous nucleation}

All our calculations are based on classical nucleation theory (CNT) (Fletcher, 1958; Reiss, 1950). Following the line presented in Gaman et al. (2004), we consider a liquid-like cluster containing $n_{1}$ molecules of water and $n_{2}$ molecules of organic acid. The formation energy of the cluster is (Laaksonen et al., 1999; Reiss, 1950):

$\Delta G_{\text {hom }}=-k T \sum_{i=1}^{2} n_{i} \ln \left(\frac{P_{i}}{P_{s, i}}\right)+4 \pi \sigma_{12} r^{2}$,

where $P_{i}$ is the ambient partial pressure of free molecules of species $i(i=1,2), P_{s, i}$ is the equilibrium vapor pressure of species $i$ above a flat solution surface, $r$ is the radius of the droplet, $\sigma_{12}$ is the surface tension of a flat liquid-vapor interface at the composition of the nucleus, $k$ is Boltzmann constant and $T$ is the temperature.

Setting $\left(\partial \Delta G_{\mathrm{hom}} / \partial n_{i}\right)_{n_{j}}=0$ yields the Kelvin equation, from which the mole fraction of, say, component 1 , denoted by $x$, and the radius of the critical cluster are obtained:

$$
\begin{aligned}
& \ln \left(\frac{P_{1}}{P_{s, 1}(x, T)}\right) v_{2}(x, T)=\ln \left(\frac{P_{2}}{P_{s, 2}(x, T)}\right) v_{1}(x, T) \\
& r^{*}=\frac{2 \sigma_{12} v_{i}}{k T \ln \left(\frac{P_{i}}{P_{s, i}}\right)},
\end{aligned}
$$

where $v_{i}$ is the partial molar volume of species $i$.

The critical formation energy is given by

$\Delta G_{\mathrm{hom}}^{*}=\frac{4}{3} \pi r^{*^{2}} \sigma_{12}$.

The nucleation rate is (Stauffer, 1976):

$I_{\text {hom }}=R_{A V} F Z \exp \left(\frac{-\Delta G_{\text {hom }}^{*}}{k T}\right)$

The evaluation of the pre-exponential part of the nucleation rate is simplified by reducing the binary system to a unary system, using the concept of virtual monomer. For nonassociated vapors, the average growth rate is:

$$
R_{A V}=\frac{R_{11} R_{22}}{R_{11} \sin ^{2} \chi+R_{22} \cos ^{2} \chi}
$$

where $R_{11}$ and $R_{22}$ are the rates at which water and organic acid molecules, respectively, collide with the critical cluster. The growth angle $\chi$ in the $\left(n_{1}, n_{2}\right)$ plane can be approximated by using $\tan \chi=\frac{x}{(1-x)}$. The total monomer concentration in the gas phase is:

$F=c_{1}+c_{2}$ 
where $c_{1}$ and $c_{2}$ are the number concentration of water and organic acid molecules in the vapor phase. In the approximation based on virtual monomer, the Zeldovich factor is given by (Kulmala and Viisanen, 1991):

$Z=\sqrt{\frac{-1}{2 \pi k T} \frac{\partial^{2} \Delta G_{\mathrm{hom}}}{\partial n^{2}}}=\sqrt{\frac{\sigma_{12}}{k T}} \frac{v}{2 \pi r^{* 2}}$

where $v=x v_{1}+(1-x) v_{2}$ is the volume of an average virtual monomer.

\subsection{Heterogeneous nucleation}

In the classical theory of heterogeneous nucleation, the seed particle is considered spherical, with a homogeneous surface. The free energy of formation of a cluster on a seed particle is (Fletcher, 1958):

$\Delta G_{\text {het }}=\Delta G_{12} V+\sigma_{12} S_{12}+\left(\sigma_{23}-\sigma_{13}\right) S_{23}$

where we denote the parent phase (vapor) with subscript 1 , the liquid embryo with 2 and the substrate with $3 . \Delta G_{12}$ represents the free energy difference per unit volume of the bulk liquid phase between liquid and vapor, $\sigma_{i j}$ is the surface free energy between phases $i$ and $j$, and $S_{i j}$ is the surface area of the interface. The composition and the radius of the critical cluster are given, as in the case of homogeneous nucleation by the Eqs. (2) and (3). The formation energy of the critical cluster is:

$\Delta G_{\text {het }}^{*}=\frac{2 \pi r^{* 2} \sigma_{12}}{3} f(m, X)=\frac{1}{2} \Delta G_{\text {hom }}^{*} f(m, X)$

with the geometrical factor

$$
\begin{aligned}
& f(m, X)=1+\left(\frac{1-m X}{g}\right)^{3}+X^{3}\left[2-3\left(\frac{X-m}{g}\right)+\right. \\
& \left.\left(\frac{X-m}{g}\right)^{3}\right]+3 m X^{2}\left(\frac{X-m}{g}-1\right)
\end{aligned}
$$

where

$g=\sqrt{1+X^{2}-2 m X}$

and $m=\cos (\theta), \theta$ is the contact angle, $X=R / r^{*}, R$ is the radius of the seed particle and $r^{*}$ is the radius of the critical cluster.

The nucleation rate per unit time and per unit area of a preexisting surface can be expressed in the similar way as in the homogeneous nucleation case (Eq. 5):

$$
I_{\text {het }}=R_{A V} F Z \exp \left(\frac{-\Delta G_{\text {het }}^{*}}{k T}\right)
$$

In the calculation of the heterogeneous nucleation rate we used the same approximate formula for the Zeldovich factor as in the homogeneous nucleation case (Eq. 8), as its use instead of the accurate treatment (see, for example, Eq. 18 in
Määttänen et al., 2007) does not affect the nucleation rate and the nucleation probability significantly. According to Vehkamäki et al. (2007) who tested both accurate and approximate Zeldovich factors on nucleation of $\mathrm{CO}_{2}$ under Martian conditions, the use of exact formulation gives higher nucleation rates than the approximate one, but the difference is less then one order of magnitude and does not affect the predicted onset conditions.

The average growth rate $R_{A V}$ is described as in the homogeneous case by Eq. (6). Two approaches are commonly used for describing the growth rate of the embryo: the direct vapor deposition and the surface diffusion. The former considers only the monomers colliding with the critical cluster, while the latter takes into account the monomers that collided and adhered to the surface of the seed particle, after which they diffuse to the cluster. Although both vapor deposition and surface diffusion take place in the same time, it is usually enough to consider only the surface diffusion, as the vapor deposition growth rate is several orders of magnitude smaller. Therefore, in this study we used the surface diffusion approach.

In heterogeneous nucleation, the number of nucleating clusters depends on the number of pre-existing seed particles. Therefore, instead of nucleation rate, it is more practical to use the concept of nucleation probability, which describes the fraction of the seed particles that became active. The nucleation probability in a time period $t$ (in this work $t=1.5 \mathrm{~s}$ ) is (Lazaridis et al., 1992):

$P=1-\exp \left(-4 \pi R^{2} I_{\text {het }} t\right)$,

where $R$ is the radius of the seed particle. We define here the onset of nucleation as the conditions where nucleation probability is $P=0.5$. In the model run, the succinic acid and glutaric acid gas phase activities (defined as the ratio between its ambient vapor pressure and the saturation vapor pressure over a flat surface of pure liquid) were varied, while the temperature and relative humidity are fixed.

\section{Thermophysical properties}

\subsection{Succinic and glutaric acids}

The activity coefficients for succinic acid-water and glutaric acid-water were calculated with van Laar method, as described in Gaman et al. (2004). All the other thermophysical properties used in the model calculations are taken from Gaman et al. (2004) with the following exceptions:

The saturation vapor pressure for succinic acid (SA) (Riipinen et al., 2006) and glutaric acid (GA) (Koponen et al., 2007):

$$
\begin{aligned}
& p_{\text {sat, }, \mathrm{SA}}=\exp \left[118.41-\frac{16204.7}{T}-12.452 \ln (T)\right] \\
& p_{\text {sat, GA }}=\exp \left[120.1915-\frac{16329.56}{T}-13.4688 \ln (T)\right]
\end{aligned}
$$


New measurements and equations for surface tension and density of succinic acid aqueous solutions from Hyvärinen et al. (2006) were included and listed below. The surface tension $\sigma$ (given in $[\mathrm{mN} / \mathrm{m}]$ ) reads:

$$
\begin{aligned}
& \sigma=\sigma_{w}\left(1-x_{S A}\right)+\sigma_{S A} x_{S A}-R T x_{S A}\left(1-x_{S A}\right) \\
& {\left[\frac{-0.101554}{x_{S A}+0.024195\left(1-x_{S A}\right)}+\frac{4.4768}{41.333 x_{S A}+\left(1-x_{S A}\right)}\right]}
\end{aligned}
$$

where $\sigma_{w}[\mathrm{mN} / \mathrm{m}]$ and $\sigma_{S A}[\mathrm{mN} / \mathrm{m}]$ represent the pure water surface tension and the supercooled succinic acid surface tension, respectively, as presented in Gaman et al. (2004), $x_{S A}$ is the succinic acid mole fraction, $T$ is the temperature and $R$ the molar gas constant. The density of the succinic acid aqueous solution is a function of the pure organic acid and water densities ( $\rho_{S A}$ and $\rho_{W}$, respectively), the molecular weights $\left(M_{S A}\right.$ and $\left.M_{W}\right)$ and the acid mole fraction:

$$
\begin{aligned}
& \frac{1}{\rho}=\frac{M_{S A} x_{S A}}{\rho_{S A}\left[M_{S A} x_{S A}+M_{W}\left(1-x_{S A}\right)\right]} \\
& +\frac{1.0082 M_{W}\left(1-x_{S A}\right)}{\rho_{W}\left[M_{S A} x_{S A}+M_{W}\left(1-x_{S A}\right)\right]}
\end{aligned}
$$

\subsection{Malonic and adipic acids}

The activity coefficients for malonic (MA) and adipic acids (AA) in aqueous solutions were calculated using UNIFAC Dortmund model (Fredenslund et al., 1975; Gmehling et al., 1990). The saturation vapor pressure is given by Riipinen et al. (2007):

$$
\begin{aligned}
& p_{\text {sat, MA }}=\exp \left[220.2389-\frac{22634.96}{T}-26.66767 \ln (T)\right] \\
& p_{\text {sat, AA }}=\exp \left[140.6704-\frac{18230.97}{T}-15.48011 \ln (T)\right]
\end{aligned}
$$

Hyvärinen et al. (2006) reports surface tension and density for binary aqueous solution of malonic acid as:

$$
\begin{aligned}
& \sigma=\sigma_{w}\left(1-x_{M A}\right)+\sigma_{M A} x_{M A}-R T x_{M A}\left(1-x_{M A}\right) \\
& {\left[\frac{-0.301717}{x_{M A}+0.073139\left(1-x_{M A}\right)}+\frac{4.1950}{13.658 x_{M A}+\left(1-x_{M A}\right)}\right]}
\end{aligned}
$$

and

$$
\begin{aligned}
& \frac{1}{\rho}=\frac{0.9984 M_{M A} x_{M A}}{\rho_{M A}\left[M_{M A} x_{M A}+M_{W}\left(1-x_{M A}\right)\right]}+ \\
& \frac{0.9929 M_{W}\left(1-x_{M A}\right)}{\rho_{W}\left[M_{M A} x_{M A}+M_{W}\left(1-x_{M A}\right)\right]}
\end{aligned}
$$

where $x_{M A}, \sigma_{M A}, \rho_{M A}$ and $M_{M A}$ represent the malonic acid mole fraction, pure subcooled liquid surface tension, density and molecular weight, respectively. The pure malonic acid surface tension is calculated with Macleod-Sugden method (Reid et al., 1987) and fitted to a linear equation:

$$
\left.\sigma_{M A}(\mathrm{mN} / \mathrm{m})\right)=87-0.13 T(\mathrm{~K}) \text {. }
$$

The pure subcooled liquid density for malonic acid is obtained using the Yen-Woods method (Yen and Woods, 1966) and its temperature dependence reads:

$\rho_{M A}\left(\mathrm{~kg} / \mathrm{m}^{3}\right)=1969.42-1.7021 T(\mathrm{~K})$.

Riipinen et al. (2007) provides new parametrization for the surface tension of adipic acid aqueous solution:

$$
\begin{aligned}
& \sigma=\sigma_{w}\left(1-x_{A} A\right)+\sigma_{A A} x_{A A}-R T x_{A A}\left(1-x_{A A}\right) \\
& {\left[\frac{1}{\Lambda_{12} x_{A A}+\left(1-x_{A A}\right)}\left(\frac{\partial \Lambda_{12}}{\partial A}\right)+\frac{1}{\Lambda_{21}\left(1-x_{A A}\right)+x_{A A}}\left(\frac{\partial \Lambda_{21}}{\partial A}\right)\right],}
\end{aligned}
$$

where $x_{A A}$ is the adipic acid mole fraction, $A$ is the surface area $\left(\mathrm{m}^{2}\right)$ and $\Lambda_{i j}$ and $\frac{\partial \Lambda_{i j}}{\partial A}(i, j=1,2)$ are the fitted parameters:

$$
\begin{aligned}
& \Lambda_{12}=\exp \left(\frac{16535.39}{R T}\right) \\
& \Lambda_{21}=\exp \left(-\frac{8392.088}{R T}\right) \\
& \frac{\partial \Lambda_{12}}{\partial A}=8.014303 \frac{\Lambda_{12}}{R T} \\
& \frac{\partial \Lambda_{21}}{\partial A}=703.0901 \frac{\Lambda_{21}}{R T}
\end{aligned}
$$

$\sigma_{A A}$ is the pure subcooled liquid surface tension for adipic acid estimated with Macleod-Sudgen method (Reid et al., 1987):

$\sigma_{A A}(\mathrm{mN} / \mathrm{m})=58.592-0.083 \mathrm{~T}(\mathrm{~K})$

The density for the adipic acid-water solution has been calculated using the ideal mixture theory, which requires the knowledge of the pure component density. As all of the studied dicarboxylic acids, pure adipic acid is solid at room temperature, but the subcooled liquid density can be calculated with Yen-Woods method (Yen and Woods, 1966). The pure liquid adipic acid density dependence on temperature was then estimated as:

$\rho_{\mathrm{AA}}\left(\mathrm{kg} / \mathrm{m}^{3}\right)=1352.56-0.6959 \times T(\mathrm{~K})$

\section{Results}

In a recent publication, Kulmala et al. (2007b) provide experimental evidence for the existence of neutral clusters in atmosphere. Their results suggest that the formation of the aerosols starts with clusters of sizes close to $1.5-2 \mathrm{~nm}$ diameter. Therefore, in our calculations, the default size for the heterogeneous nucleation of water-dicarboxylic acids mixtures on solid, spherical particles is $1 \mathrm{~nm}$ radius. The default values for temperature, relative humidity and contact angle were fixed at $273 \mathrm{~K}, 70 \%$ and 0 degrees (complete wetting), respectively. The parameters are varied one at a time while the others are kept constant, unless otherwise stated. 


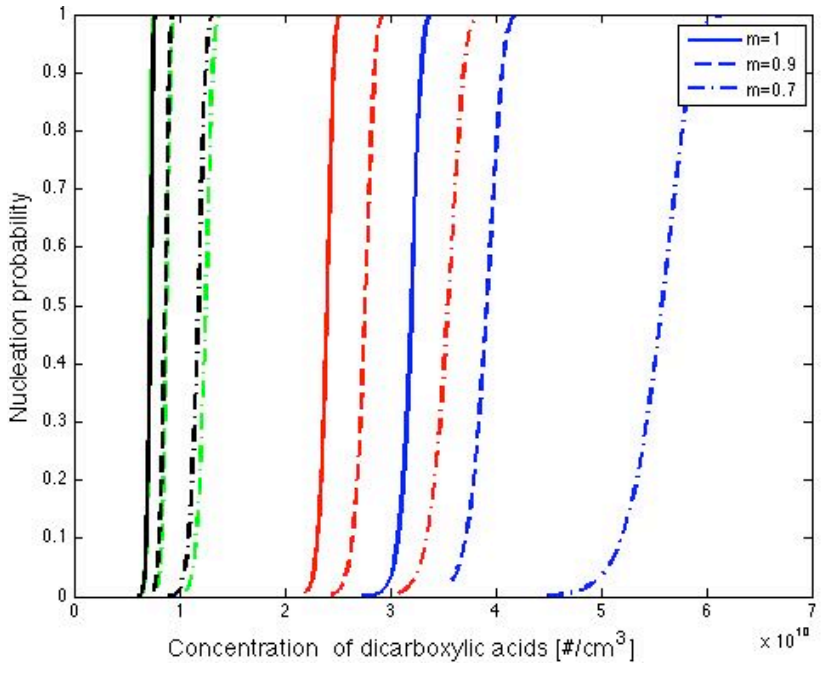

Fig. 1. Nucleation probability for dicarboxylic acids-water system vs. dicarboxylic acid concentration in gas phase. The radius of the seed particle is $1 \mathrm{~nm}, T=273 \mathrm{~K}$ and $\mathrm{RH}=70 \%$. The three curves correspond to different values of the contact angle and the colors represent each dicarboxylic acid: blue - succinic acid, red - glutaric acid, green - malonic acid and black - adipic acid.

Contact angle variation. In reality, the contact angle changes as a function of the critical cluster composition, but, due to the lack of experimental data for these four specific systems, our calculations were performed at three constant contact angles: $m=1\left(\theta=0^{\circ}\right), 0.9\left(\theta=25.84^{\circ}\right)$ and 0.7 $\left(\theta=45.5^{\circ}\right)$, respectively, where $m$ is the the cosine of the contact angle $\theta$. The nucleation probabilities for heterogeneous nucleation were calculated and the nucleation rates in case of homogeneous nucleation were considered also for comparison.

The nucleation probabilities depend on the contact angle, but not significantly, especially for glutaric acid, malonic acid and adipic acid-water systems. The most sensitive system to contact angle variation is succinic acid-water (Fig. 1). We note the different slopes of the nucleation probabilities: the slopes become steeper with decreasing contact angle. As expected, the smallest concentration of dicarboxylic acid necessary for heterogeneous nucleation is obtained for totally wettable seed particles.

The homogeneous nucleation rates calculated with the new thermodynamics and same temperature and relative humidity conditions as the heterogeneous nucleation are depicted in Fig. 2. For succinic, glutaric acid and malonic systems, the concentrations of organic molecules in gas phase necessary for homogeneous nucleation is about one order of magnitude higher than the lowest concentration needed for heterogeneous nucleation, while in the case of adipic acid, the homogeneous nucleation seems to be more favourable.

Seed particle size variation. The size of the seed particles is varied in the next step. Eight different radii are con-

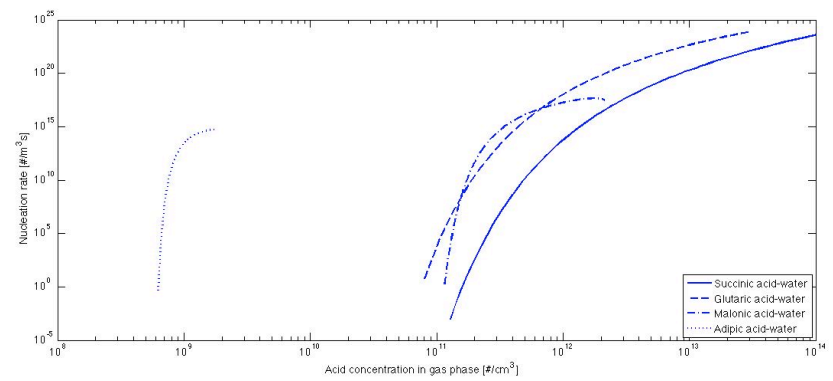

Fig. 2. Modeled homogeneous nucleation rate for dicarboxylic acid-water system vs. dicarboxylic acid concentration in gas phase in the same temperature and relative humidity conditions as for the heterogeneous nucleation.

sidered, ranging from $0.5 \mathrm{~nm}$ radius up to $100 \mathrm{~nm}$ radius, as shown in Fig. 3. Although the smallest seed particles (here $0.5 \mathrm{~nm}$ radius) are less effective than the larger seeds in reducing the nucleation barrier, they are still clearly able to promote nucleation. For radii larger than $5 \mathrm{~nm}$, the calculated nucleation probabilities show almost no variation with the size of the seed particle. A larger seed particle lowers the concentration of the organic acid needed for heterogeneous nucleation with another order of magnitude, in comparison with the nucleation on $2 \mathrm{~nm}$ size preexisting particles. According to the data presented by Limbeck et al. (2005), the gas phase concentration for both glutaric and succinic acids is of the order of $10^{13}$ molecules $/ \mathrm{m}^{3}$, i.e., about 2 orders of magnitude smaller than our estimations for heterogeneous nucleation and 4 orders of magnitude smaller than for the homogeneous nucleation case. For comparison purpose, the nucleation probabilities of all four dicarboxylic acids on particles of $1 \mathrm{~nm}$ radius are shown in the same plot (Fig. 4). It should be noted that the heterogeneous nucleation of malonic and adipic acids takes place at similar concentrations in gas phase, the only difference being a slightly steeper slope of the nucleation probability curve in case of adipic acid-water system.

Relative humidity and temperature variation. The water vapor content in the atmosphere is expected to affect the rate of nucleation. In Fig. 5 we present nucleation probabilities calculated for three relative humidities $(50 \%, 70 \%$ and $90 \%$, respectively). The influence of relative humidity on the nucleation rate is relatively weak in the studied range and becomes insignificant in case of adipic acid. A summary of $t$ he dependence of nucleation probability on changes in temperature is given in Fig. 6 for five different temperatures (253$293 \mathrm{~K}$ ) demonstrating that temperature is the most important parameter in governing the binary nucleation rate in dicarboxylic acids-water systems. At lower temperatures, the acid concentrations in the gas phase are lowered by $2-3$ orders of magnitude in comparison with the default values. Figure 7 presents the nucleation probabilities of the four systems for the lowest temperature, $253 \mathrm{~K}$. Malonic acid nucleation is 

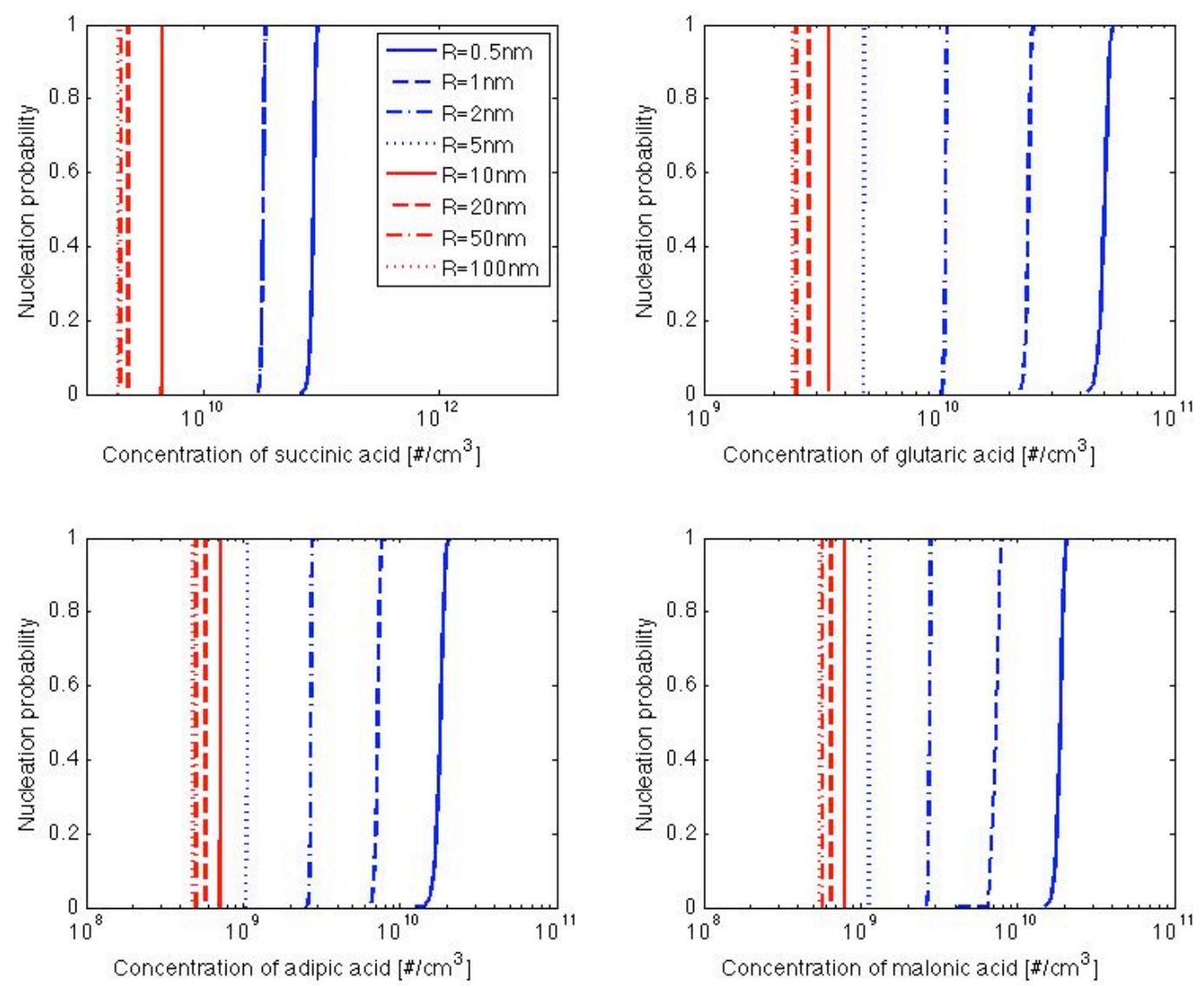

Fig. 3. Nucleation probability for dicarboxylic acids-water system vs. dicarboxylic acid concentration in gas phase. The radius of the seed particle is varied while temperature, relative humidity and contact angle are fixed at $T=273 \mathrm{~K}, \mathrm{RH}=70 \%$ and $m=1$.

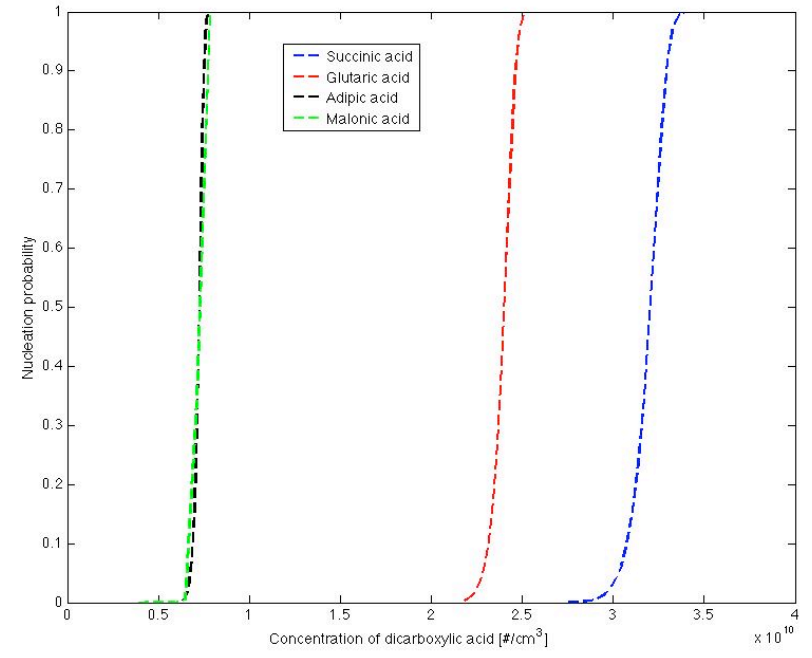

Fig. 4. Nucleation probability for dicarboxylic acids-water system vs. dicarboxylic acid concentration in gas phase. The radius of the seed particle is $1 \mathrm{~nm}$ and the temperature, relative humidity and contact angle are fixed at $T=273 \mathrm{~K}, \mathrm{RH}=70 \%$ and $m=1$.

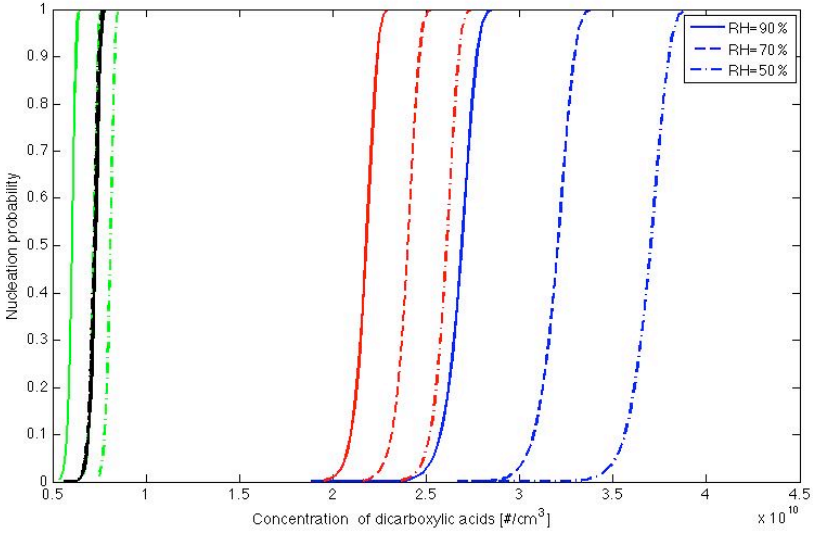

Fig. 5. Nucleation probability for dicarboxylic acids-water system vs. dicarboxylic acid concentration in gas phase. The relative humidity is varied while temperature, radius of the seed particle and contact angle are fixed at $T=273 \mathrm{~K}, \mathrm{RH}=1 \mathrm{~nm}$ and $m=1$. The colors represent each dicarboxylic acid: blue - succinic acid, red - glutaric acid, green - malonic acid and black - adipic acid. 


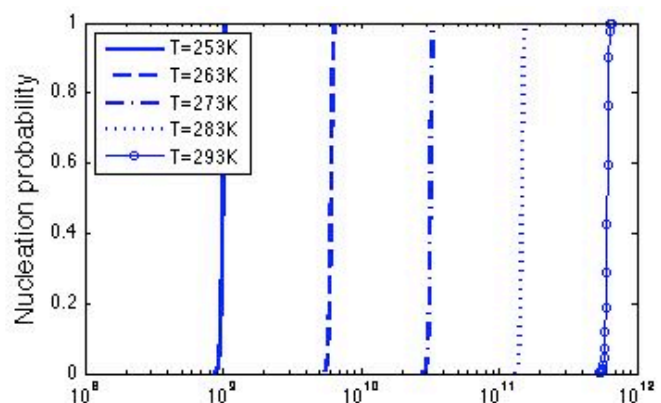

Concentration of succinic acid molecules $\left[\# / \mathrm{cm}^{3}\right]$

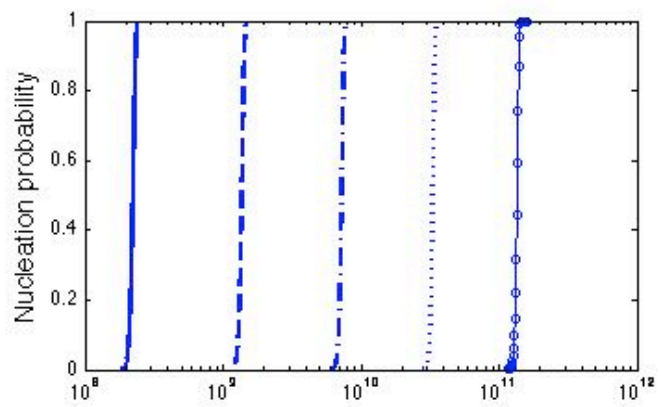

Concentration of adipic acid molecules $\left[\# / \mathrm{cm}^{3}\right]$

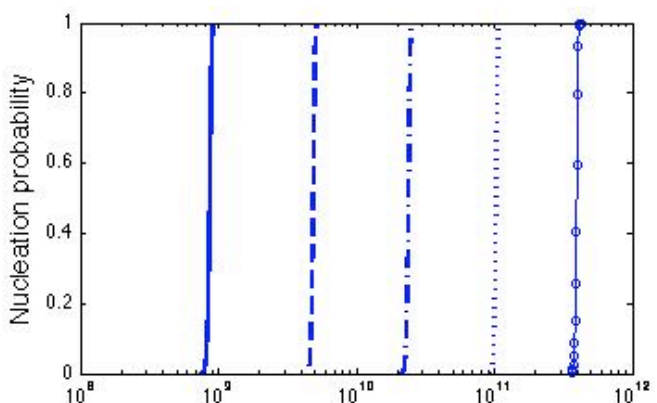

Concentration of glutaric acid molecules $\left[\# / \mathrm{cm}^{3}\right]$

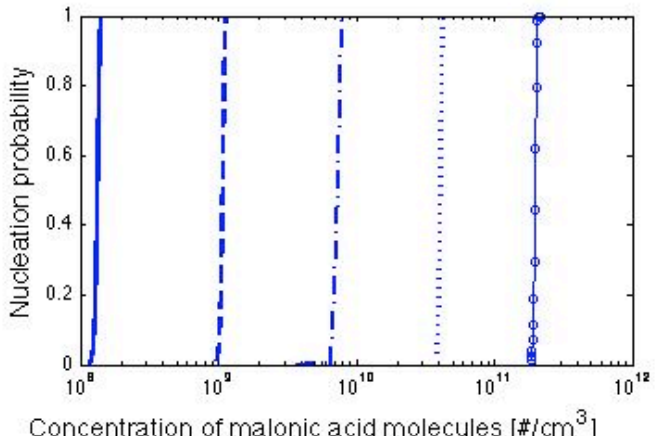

Fig. 6. Nucleation probability for dicarboxylic acids-water system vs. dicarboxylic acid concentration in gas phase. The ambient temperature is varied while radius of the seed particle, relative humidity and contact angle are fixed at $R=1 \mathrm{~nm}, \mathrm{RH}=70 \%$ and $m=1$.

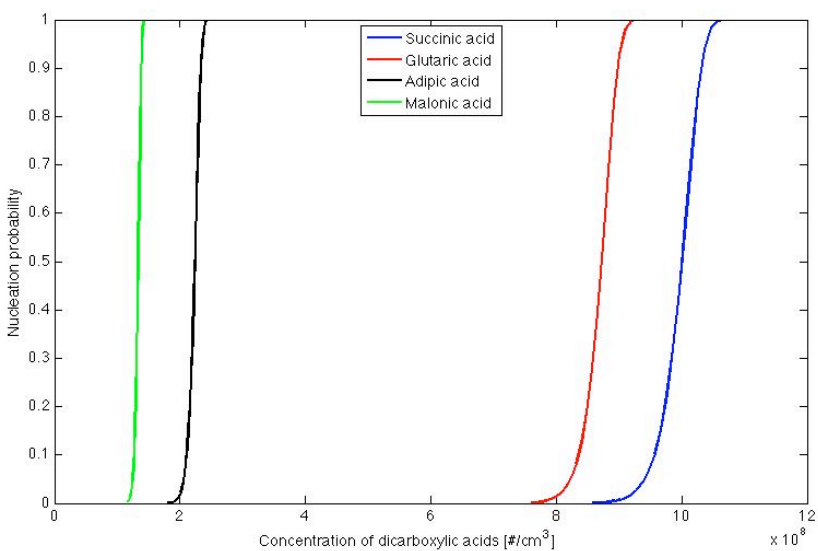

Fig. 7. Nucleation probability for dicarboxylic acids-water system vs. dicarboxylic acid concentration in gas phase. The ambient temperature is $253 \mathrm{~K}$ and radius of the seed particle, relative humidity and contact angle are fixed at $R=1 \mathrm{~nm}, \mathrm{RH}=70 \%$ and $m=1$. The colors represent each dicarboxylic acid: blue - succinic acid, red glutaric acid, green - malonic acid and black - adipic acid.

achieved for the lowest concentration in gas phase, followed closely by the adipic acid.

It is worth to note here the importance of well defined equations for the saturation vapor pressure in the calculation of nucleation rates. In Gaman et al. (2004), we esti-

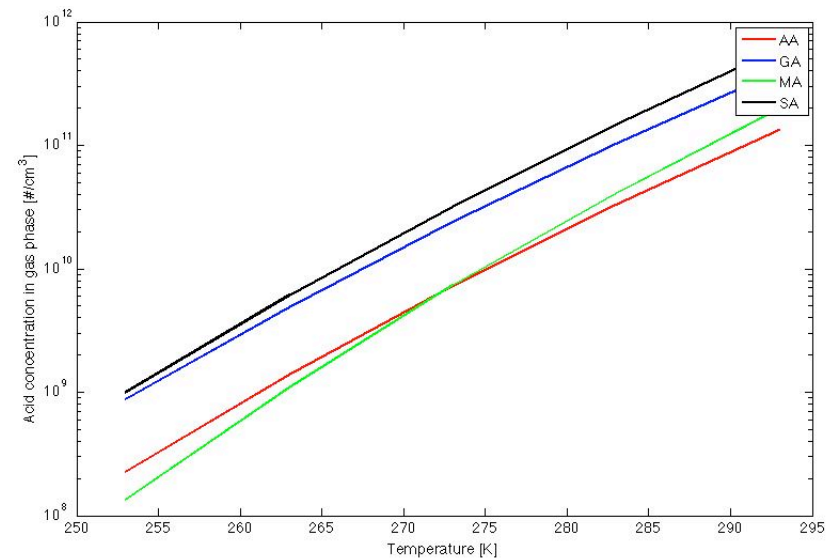

Fig. 8. Modeled onset activities for the dicarboxylic acid-water systems vs. temperature. The radius of the seed particle, relative humidity and contact angle are fixed at $R=1 \mathrm{~nm}, \mathrm{RH}=70 \%$ and $m=1$.

mated the subcooled liquid state vapor pressure for succinic acid and glutaric acid by converting the solid state vapor pressure as described in Prausnitz et al. (1999). According to the numerical calculations, the systems reached a relevant nucleation rate (for example larger then 1 particle $/ \mathrm{cm}^{3} \mathrm{~s}$ ) when the concentration of dicarboxylic acids was around $10^{15}$ molecules $/ \mathrm{cm}^{3}$. The more recent equations for the va- 
por pressure presented in the previous section reduced the concentration of the organic acid in gas phase needed for the homogeneous nucleation by about $2-3$ orders of magnitude. The use of the new surface tension and density models (Eqs. 17 and 18) instead of the original ones from Gaman et al., 2004 does not change the result significantly.

In Fig. 8 the modeled onset activities for the organic acidwater systems for different values of temperature are shown. The curves are smooth and the near linearity of the onset curves manifests the fact that the water and the four dicarboxylic acids are close to an ideal mixture. A resembling behavior has been observed for the homogeneous nucleation of water-succinic acid (Gaman et al., 2004).

\section{Concluding remarks}

Using the classical theory of heterogeneous nucleation, we have analyzed the droplet formation for four dicarboxylic acids (succinic, glutaric, malonic and adipic acids)-water systems on spherical, solid particles.

According to our calculations, heterogeneous nucleation is more effective than homogeneous nucleation for three of the acids (succinic, glutaric and malonic), when seed particles are larger than $2 \mathrm{~nm}$; also smaller seed particles sizes will enhance the particle formation. For these acids the computed gas phase concentrations (like for succinic and glutaric acids) are about 2-3 orders of magnitude higher than the measured ones (Limbeck et al., 2005). The fact that heterogeneous nucleation is more effective than homogenous nucleation is also verified recently in laboratory experiments (Winkler et al., 2008). The only exception is the adipic acid-water system, for which the homogeneous nucleation seems to be more favourable.

However, the investigated acids can participate in the atmospheric particle formation at low temperatures, like in upper troposphere and lower starosphere (UTLS). Deep convection could bump gases to this area, where new particle formation could occur (Kulmala et al., 2006). The other possible environment to achieve new particle production via binary heterogeneous nucleation of these acids is cold urban environment with high vapour concentrations.

In our calculations we considered the seed particle as spherical, with homogeneous surface and the interactions between the surface and the nucleating molecules have been included only roughly by means of a constant the contact angle, for which several values were tested. Future work should address the effects of the surface in more detail, as substrates with different wetting properties are expected to influence drastically the values of the concentration in gas phase required for heterogeneous nucleation. This can be done by considering a well characterized substrate composition and size dependent contact angle and through the inclusion of the concept of line tension. However, the theoretical calculations can not be improved and verified without experimental data.
Reliable data for parameters like contact angle or activity coefficients are needed to improve the present calculations and then apply them in atmospheric models.

Acknowledgements. The Academy of Finland is gratefully acknowledged for financial support.

Edited by: A. Wiedensohler

\section{References}

Allan, J. D., Alfarra, M. R., Bower, K. N., Coe, H., Jayne, J. T., Worsnop, D. R., Aalto, P. P., Kulmala, M., Hyötyläinen, T., Cavalli, F., and Laaksonen, A.: Size and composition measurements of background aerosol and new particle growth in a Finnish forest during QUEST 2 using an Aerodyne Aerosol Mass Spectrometer, Atmos. Chem. Phys., 6, 315-327, 2006,

http://www.atmos-chem-phys.net/6/315/2006/.

Fletcher, N.: Size effect in heterogeneous nucleation, J. Chem. Phys, 29, 572-576, 1958.

Fredenslund, A., Jones, R. J., and Prausnitz, J. M.: Groupcontribution estimation of activity coefficients in nonideal liquid mixtures, AIChE J., 21, 1086-1099, 1975.

Gaman, A., Kulmala, M., Vehkamäki, H., Napari, I., Mircea, M., Facchini, M., and Laaksonen, A.: Binary homogeneous nucleation in water-succinic acid and water-glutaric acid systems, J. Chem. Phys., 120, 282-291, 2004.

Gmehling, J., Tiegs, D., and Knipp, U.: A comparison of the predictive capability of different group contribution methods, Fluid Phase Equilib., 54, 147-165, 1990.

Grosjean, D., Van Cauwenberghe, K., Schmid, J. P., Kelley, P. E., and Pitts, J. N. J.: Identification of C3 C10 aliphatic dicarboxylic acids in airborne particulate matter, Environ. Sci. Technol., 12, 313-317, 1978.

Hyvärinen, A. P., Lihavainen, H., Gaman, A., Vairila, L., Ojala, H., Kulmala, M., and Viisanen, Y.: Surface tensions and densities of oxalic, malonic, succinic, maleic, malic and cis-pinonic acids, J. Chem. Eng. Data, 51, 255-260, 2006.

Kanakidou, M., Seinfeld, J. H., Pandis, S. N., Barnes, I., Dentener, F. J., Facchini, M. C., VanDingenen, R., Ervens, B., Nenes, A., Nielsen, C. J., Swietlicki, E., Putaud, J. P., Balkanski, Y., Fuzzi, S., Horth, J., Moortgat, G. K., Winterhalter, R., Myhre, C. E. L., Tsigaridis, K., Vignati, E., Stephanou, E. G., and Wilson, J.: Organic aerosol and global climate modelling: a review, Atmos. Chem. Phys., 5, 1053-1123, 2005,

http://www.atmos-chem-phys.net/5/1053/2005/.

Kawamura, K., Kasukabe, H., and Barrie, L.: Source and reaction pathways of dicarboxylic acids, ketoacids and dicarbonyls in arctic aerosols: one year of observations., Atmos. Environ., 30, 1709-1722, 1996.

Kerminen, V. M., Pirjola, L., and Kulmala, M.: How signifigantly does coagulation scavening limit atmospheric particle production?, J. Geophys. Res., 106, 24119-24125, 2001.

Koponen, I., Riipinen, I., Hienola, A., Kulmala, M., and Bilde, M.: Thermodynamic properties of malonic, succinic and glutaric acids: evaporation rates and saturation vapor pressures, Environ. Sci. Technol., 41, 3926-3933, 2007. 
Kulmala, M.: How Particles Nucleate and Grow, Science, 302, 1000-1001, 2003.

Kulmala, M. and Viisanen, Y.: Homogeneous Nucleation: Reduction of Binary Nucleation to Homomolecular Nucleation, J. Aerosol Sci., 22, S97-S100, 1991.

Kulmala, M., Kerminen, V.-M., Anttila, T., Laaksonen, A., and O'Dowd, C.: Organic aerosol formation via sulphate cluster activation, J. Geophys. Res., 109, D04205, 10.1029/2003JD003 961, 2004a.

Kulmala, M., Vehkamäki, H., Petäjä, T., Dal Maso, M., Lauri, A., Kerminen, V.-M., Birmili, W., and McMurry, P.: Formation and growth rates of ultrafine atmospheric particles: a review of observations, J. Aerosol Sci., 35, 143-176, 2004b.

Kulmala, M., Lehtinen, K. E. J., and Laaksonen, A.: Cluster activation theory as an explanation of the linear dependence between formation rate of $3 \mathrm{~nm}$ particles and sulphuric acid concentration, Atmos. Chem. Phys., 6, 787-793, 2006, http://www.atmos-chem-phys.net/6/787/2006/.

Kulmala, M., Mordas, G., Petäjä, T., Grönholm, T., Aalto, P., Vehkamäki, H., Hienola, A. I., Herrmann, E., Sipilä, M., Riipinen, I., Manninen, H., Hämeri, K., Stratmann, F., Bilde, M., Winkler, P., Birmili, W., and Wagner, P.: The condensation particle counter battery $(\mathrm{CPCB})$ : A new tool to investigate the activation properties of nanoparticles, J. Aerosol Sci., 38, 289-304, 2007a.

Kulmala, M., Riipinen, I., Sipilä, M., Manninen, H. E., Petäjä, T., Junninen, H., Dal Maso, M., Mordas, G., Mirme, A., Vana, M., Hirsikko, A., Laakso, L., Harrison, R. M., Hanson, I., Leung, C., Lehtinen, K. E. J., and Kerminen, V.: Toward direct measurement of atmospheric nucleation, Science, 318, 89-92, $2007 \mathrm{~b}$.

Laaksonen, A., McGraw, R., and Vehkamäki, H.: Liquid-drop formalism and free-energy surfaces in binary homogeneous nucleation theory, J. Chem. Phys., 111, 2019-2027, 1999.

Lazaridis, M., Kulmala, M., and Gorbunov, B. Z.: Binary heterogeneous nucleation at a non-uniform surface, J. Aerosol Sci., 23, 457-466, 1992.

Limbeck, A., Kraxner, Y., and Puxbaum, H.: Gas to particle distribution of low molecular weight dicarboxylic acids at two different sites in Central Europe (Austria), J. Aerosol Sci., 36, 9911005,2005

Määttänen, A., Vehkamäki, H., Lauri, A., Napari, I., and Kulmala, M.: Two-component heterogeneous nucleation kinetics and an application to Mars, J. Chem. Phys., 127, 11 pp., 134710, 2007.
O’Dowd, C. D., Aalto, P., Hämeri, K., Kulmala, M., and Hoffmann, T.: Atmospheric particles from organic vapours, Nature, 416, 497-498, 2002.

Prausnitz, J. M., Lichtenthaler, R. N., and de Azevedo, E. G.: Molecular thermodynamics of fluid-phase equilibria, 3rd edn., Prentice Hall PTR, Upper Saddle River, New Jersey, USA, 638640, 1999.

Poling, B. E., Prausnitz, J. M. O'Connell, J. P.: Properties of Gases and Liquids, 5th edn., McGraw-Hill, 12.13-12.15, 2001.

Reiss, H.: The kinetics of Phase Transitions in Binary Systems, J. Chem. Phys., 18, 840-848, 1950.

Riipinen, I., Svenningsson, B., Bilde, M., A., G., Lehtinen, K., and Kulmala, M.: A method for determining thermophysical properties of organic material in aqueous solutions: Succinic acid, Atm. Res., 82, 579-590, 2006.

Riipinen, I., Koponen, I., Frank, G., Hyvärinen, A., Vanhanen, J., Lihavainen, H., Lehtinen, K., Bilde, M., and Kulmala, M.: Adipic and malonic acid aqueous solutions: surface tensions and saturation vapor pressures, J. Chem. Phys., 111, 12995-13002, 2007.

Rohrl, A. and Lammel, G.: Determination of malic acid and other C4 dicarboxylic acids in atmospheric aerosol samples, Chemosphere, 46, 1195-1199, 2002.

Stauffer, D.: Kinetic theory of two-component ('Heteromolecular') nucleation and condensation, J. Aerosol Sci., 7, 319-333, 1976.

Tunved, P., Hansson, H.-C., Kerminen, V.-M., Strom, J., M., D., Lihavainen, H., Viisanen, Y., Aalto, P., Komppula, M., and Kulmala, M.: High natural aerosol loading over boreal forests, Science, 312, 261-263, 2006.

Vehkamki, H., Määttänen, A., Lauri, A., Napari, I., and Kulmala, M.: Technical Note: The heterogeneous Zeldovich factor, Atmos. Chem. Phys., 7, 309-313, 2007, http://www.atmos-chem-phys.net/7/309/2007/.

Winkler, P., Steiner, G., Vrtala, A., Vehkamaki, H., Noppel, M., Lehtinen, K., Reischl, G., Wagner, P., and Kulmala, M.: Heterogeneous nucleation experiments bridging the scale from molecular ion clusters to nanoparticles, Science, 319(5868), 1374-1377, 2008.

Yen, L. and Woods, S. S.: A generalized equation for computer calculation of liquid densities, AIChE J., 12, 95-99, 1966. 